\title{
ポリゴン型壁境界MPS法の特徴および防波堤越流津波への適用
}

\section{Characteristics of MPS Method using Polygon-Wall Boundary and its Application to Tsunami Overflowing Breakwater}

\author{
小笠原敏記 ${ }^{1}$ ・亀尾実愛 ${ }^{2} \cdot{\text { 佐々木 } \text { 智 }^{3} \text { ・砂川透吾 }}^{4}$ \\ Toshinori OGASAWARA, Minori KAMEO, Satoru SASAKI and Togo SUNAGAWA
}

\begin{abstract}
The purpose of our study is to develop numerical simulation to investigate the toughness of tsunami disaster countermeasures.Moving Particle Semi-implicit (MPS) method was used in the simulation. The wall boundary was applied polygon-wall boundary instead of particle-wall boundary.As the result, we suggested that MPS used the polygonwall boundary is possible to calculate with high accuracy fluid dynamics than particle-wall boundary.Furthermore, in the simulation of tsunami overflowing the breakwater, the presented method was able to reproduce vortexes generated by the tsunami. The values of velocity also were in agreement with that of the model experiments.It was obvious that the roll-up flow accompanied with vortexes on a mound will be scouring of the surface of the mound.
\end{abstract}

\section{1. 序論}

2011 年東北地方太平洋沖地震津波によって, 沿岸部に 位置する海岸保全施設を始め, 港湾施設や交通施設等の 公共土木施設も大きな被害を受けた。湾口防波堤や第一 線防波堤の被災原因として，防波堤を越流した津波によ って堤体背後のマウンドが洗掘され，ケーソンの支持力 の低下や，設計津波高を超えた津波によって堤体沖側と 岸側の水位差によるケーソンの不安定化による転倒が考 えられる. 加えて, 引き波の作用によって, 構造的に弱 い堤体沖側への崩壊が進んだことも報告されている（有 川ら, 2012).

海岸堤防には, 津波の陸域への浸水低減の効果や, 到 達時間遅延の役割が期待される。そのため，被災した堤 防の復旧や既設堤防の改修および強化には，設計超過外 力が作用した場合においても最低限の機能を維持する粘 り強さが必要とされる．佐藤ら（2012）は，防波堤の安 定性を高めるため, 防波堤を越流する津波に関する水理 模型実験を行い, CADMAS - SURFを用いた数值計算に よる再現性を試みているが, 堤体岸側背後の水面変動や 流速があまり一致しないことから，入射波条件の設定が 適宜必要であることを報告している。

そこで本研究では, 堤体を越流する津波の再現計算と して粒子法のMPS法を用いるが，原田ら（2008）が提案 した壁境界モデルを改良したポリゴン型壁境界を構造物 に適用した場合，従来の粒子型壁境界よりも計算精度が 向上することを示唆する，さらに，越流洗掘型の被災事

\begin{tabular}{|c|c|c|}
\hline 正会員 & 博 (工) & 岩手大学准教授工学部社会環境工学科 \\
\hline 学生会員 & & $\begin{array}{l}\text { 岩手大学大学院工学研究科社会環境工学 } \\
\text { 専攻 }\end{array}$ \\
\hline & 修 (工) & 東日本旅客鉄道(株)仙台支社 \\
\hline & 修 (工) & クコンサルタンツ(株) \\
\hline
\end{tabular}

例の水理模型実験を比較対象として，流入境界を加えた 本計算手法を用いることによって, 堤体背後の流体運動 の再現性が高いことを実証する.

\section{2. 計算手法}

非圧縮性流体の支配方程式は，式（1）および（2）に示 す連続の式とナビエ・ストークス方程式である.

$$
\begin{aligned}
& \nabla \cdot \vec{v}=0 \\
& \frac{D \vec{v}}{D t}=\frac{1}{\rho} \nabla P+v \nabla^{2} \vec{v}+\vec{g}
\end{aligned}
$$

ここで， $\vec{v}$ は速度べクトル， $t$ は時間， $\rho$ は密度， $P$ は圧 力, $v$ は動粘性係数, $\vec{g}$ は重力加速度である. MPS 法で は，微分演算子に対応する粒子間相互作用モデルを用い て連続体の支配方程式を離散化するものであり, 式 (3) 〜 (5) の勾配モデル, ラプラシアンモデル, および発散 モデルを適用する.

$$
\begin{aligned}
& \langle\nabla \phi\rangle_{i}=\frac{d}{n^{0}} \sum_{j \neq i}\left[\frac{\phi_{j}-\phi_{i}}{r_{i j}^{2}} \vec{x}_{i j} w_{i j}\right] \\
& \left\langle\nabla^{2} \phi\right\rangle_{i}=\frac{2 d}{n^{0} \lambda} \sum_{j \neq i}\left[\left(\phi_{j}-\phi_{i}\right) w_{i j}\right] \\
& \langle\nabla \cdot \vec{u}\rangle_{i}=\frac{d}{n^{0}} \sum_{j \neq i}\left[\frac{\vec{u}_{i j} \cdot \vec{x}_{i j}}{r_{i j}^{2}} w_{i j}\right] .
\end{aligned}
$$

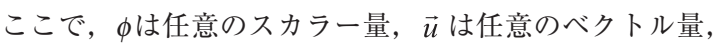
$n^{0}$ は基準粒子数密度, $w_{i j}$ は粒子 $i, j$ 間の重み関数, $r_{i j}$ は 粒子間の距離, $d$ は次元数, $\vec{x}_{i j}\left(=\vec{r}_{j}-\vec{r}_{i}\right)$ は各粒子の座標で ある. また， $\lambda$ は変数分布の分散を解析解と一致させる 
ための係数である.

非圧縮条件は，粒子数密度が基準粒子数密度と等しい という PND条件と, 速度の発散がゼロという DIV 条件で あり，式（6）に示す圧力のポアソン方程式を用いる.

$$
\nabla^{2} P=\frac{\rho}{\Delta t} \nabla \cdot \vec{v}^{*}+\frac{\rho}{\Delta t^{2}} \frac{n^{0}-n^{*}}{n^{0}}
$$

ここで， $\Delta t$ は時間ステップ， $\vec{v}^{*}$ および $n^{*}$ は圧力項以外を 陽的に解いた後の仮の速度㧍よび粒子数密度である。な お，圧力のポアソン方程式を解く際，自由表面粒子の圧 カがゼロであるという境界条件を用いる. 自由表面の判 定には，式 (7)に示す粒子数密度を用いる.

$$
n_{i}<c n^{0}
$$

ここで, $c$ は表面判定のための係数であり, 計算の安定 性を考慮して $c=0.80$ とした

\section{3. ポリゴン型壁境界の特徵}

\section{（1）ポリゴン型壁境界}

MPS 法にポリゴン型壁境界を適用させる場合，流体粒 子がポリゴンの壁に近づいたときの相対位置が必要であ る. 本計算の前処理として計算領域を格子分割し, 各格 子点とポリゴンとの距離関数掞よび単位法線ベクトルの データベース化を行う．本計算では，データベースから 流体粒子とポリゴンの壁までの最短距離を求め，その距 離を基に，壁近傍における圧力のポアソン方程式，圧力 項および粘性項をそれぞれ流体粒子とポリゴン型壁境界 との二つの項の和で表す（佐々木・小笠原，2012）。圧力 のポアソン方程式は，壁近傍においても PND条件とDIV 条件を满足するように計算する. 特に, 式 (6) の右辺第 1 項は, 式 (5)の発散モデルを用いて式 (8)のように表される.

$$
\left\langle\nabla \cdot \vec{v}^{*}\right\rangle_{\text {wall }}=\frac{d}{n^{0}}\left[\frac{\vec{v}_{i j}^{*}}{r_{i j}^{2}} \vec{x}_{i j} w_{i j}\right]
$$

式 (8)の相対速度ベクトル $\vec{v}_{i j}^{*}$ は, 法線方向成分のみで表す ことができ, 壁境界の単位法線ベクトルを用いると, 式 (9) で表すことができる.

$$
\left\langle\nabla \cdot \vec{v}^{*}\right\rangle_{\text {wall }}=\frac{d}{n^{0}}\left|\vec{v}_{i j}^{*} \cdot \vec{n}_{\text {wall }}\right| w_{d}
$$

ここで， $\vec{n}_{\text {wall }}$ は壁境界の単位法線ベクトル， $w_{d}$ は流体粒 子と壁との間の重み関数である.

壁近傍における圧力項では，流体粒子が壁から受ける 力を壁の法線方向のみと仮定し, 式 (10)に示すように減衰 力および反発力の和として表す.

$$
\langle\nabla P\rangle_{\text {wall }}=\langle\nabla P\rangle_{\text {wall }}^{\text {Damp }}+\langle\nabla P\rangle_{\text {wall }}^{\text {Spring }}
$$

式 (10)の右辺第 1 項は, 流体粒子が壁に近づくに連れて, そ の速度が減速し, 壁に接触したときにゼロになることを考慮 して, 式(11)のように表される.

$$
-\frac{1}{\rho}\langle\nabla P\rangle_{\text {wall }}^{\text {Damp }}=\left\{\begin{array}{lc}
\frac{\left|\vec{v}_{i j}^{*}\right|}{\Delta t} & \left(r_{i j} \leq 0.5 L\right) \\
\frac{R-r_{i j}}{R-0.5 L} \frac{\left|\vec{v}_{i j}^{*}\right|}{\Delta t} & \left(0.5 L<r_{i j}\right)
\end{array}\right.
$$

ここで, $R$ は影響半径, $L$ は粒子径である.また, 式 $(10)$ の 右辺第2 項は, 原田ら (2008)を基にペナルテイ法を用いて, 流体粒子と壁との間に若干のめり込み量を考慮し, その量 に応じた反発力を作用させて式 (12)のように表される.

$$
-\frac{1}{\rho}\langle\nabla P\rangle_{\text {wall }}^{\text {Spring }}=c_{r} \frac{0.5 L-r_{i j}}{\Delta t^{2}} \quad\left(r_{i j} \leq 0.5 L\right)
$$

ここで, $c_{r}$ は反発係数であり,$c_{r}=0.25$ とした.

さらに, 壁近傍の粘性項では, 式 (4) のラプラシアンモデ ルを用いて，式（13）のように表される.

$$
\left\langle\nabla^{2} \vec{v}\right\rangle_{\text {wall }}=\frac{2 d}{\lambda n^{0}} \sum_{j \in \text { wall }}\left[\vec{v}_{i j} w_{i j}\right]=\frac{2 d}{\lambda n^{0}} \vec{v}_{i j} n_{w}
$$

ここで， $n_{w}$ は壁粒子数密度であり, 流体粒子とポリゴン の壁までの最短距離に依存した值である。なお，式 (8) から (13)までの変数 $j$ はポリゴンの壁の位置に相当する.

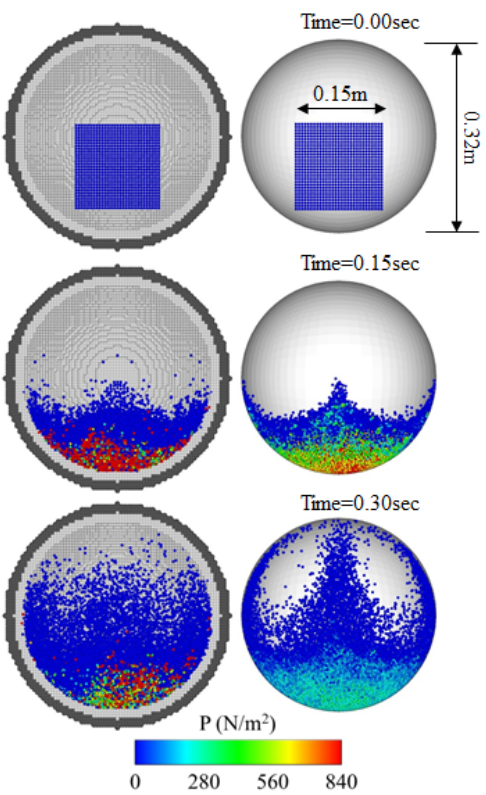

図-1 球体内の水塊落下時の空間および圧力分布 (左側：粒子型壁境界，右側：ポリゴン型壁境界) 


\section{（2）粒子型壁境界との比較}

従来の粒子型壁境界と流体運動を比較するため, 直径 $0.32 \mathrm{~m}$ の球状の壁境界を粒子型（壁粒子数 92,490 個）打よ びポリゴン型についてそれぞれ構築し, 球体内に立方体

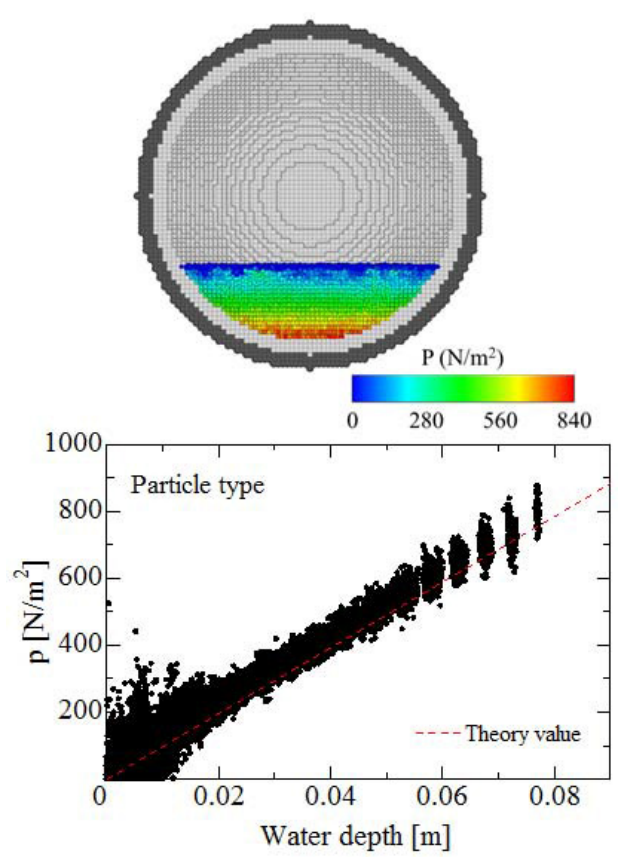

（a）粒子型壁境界

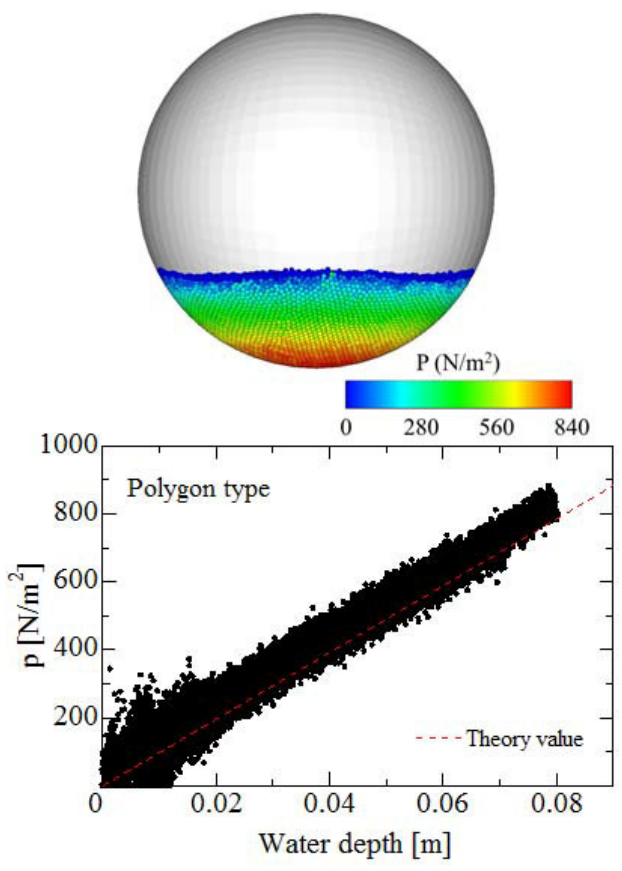

(b) ポリゴン型壁境界

図-2 球体内の水塊落下後の静的状態での圧力分布
の水塊を自由落下させる計算を行う。図-1は，球体内に おける水塊の落下過程の空間変化と圧力分布を示す. 粒 子型の計算結果に比べてポリゴン型では，水塊の壁面衝 突に伴う水面変形は，対称性を保ちながら壁の曲面に沿 うように滑らかに上昇する。また，粒子型に見られるよ うな圧力值の急激な変化やバラツキがなく, 水面から梁 くなるに連れて高くなるような安定した圧力分布である. さらに, 落下後の静的状態における圧力の比較を図-2に 示す. 粒子型では, 壁面近傍で圧力が算出されない場所 が存在するが，この原因として個々の球状粒子で壁を構 成しているため, 壁面の粒子間の凹凸による不連続性が 必然的に生じる，その凹凸と流体粒子の衝突が粒子法特 有の圧力振動を助長させることによって, 流体粒子間に 空隙が発生し, 式 (7)により自由水面粒子（圧力ゼロ）と 判断されたためと推察される. 一方のポリゴン型では，凹 凸のない滑らかな壁面を構築することができるため, 静 水圧分を示す理論值に近い分布になることがわかる.

以上より，ポリゴン型壁境界は，従来の粒子型壁境界 よりも，流体運動の変形過程打よびその圧力分布を高精 度に表すことが可能と言える。

\section{4. 防波堤越流計算}

ここでは，流入・流出境界を設けたポリゴン型壁境界 による一般防波堤を越流する津波の再現計算を行い，越 流洗掘型の被災事例の模型実験との比較検証より, 堤体 背後での津波の流体運動の再現性が高いことを実証する.

（1）流入・流出境界

流入境界は, 計算領域の外側に 3 層の流入粒子を配置 し，流入速度を与える．各層の粒子の移動距離が粒子径 $L$ 以上になったとき，最内側 1 層目の流入粒子を流体粒子 に変換し，新たに3 層目に流入粒子を配置する。このと き，1層目と2層目の流入粒子は，安定に計算するために 圧力計算を行う。一連の操作を繰り返すことによって,
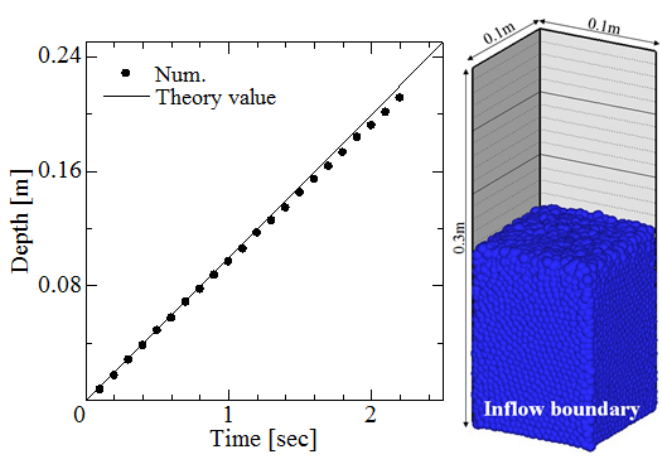

図-3 流入境界を考慮した計算領域（右側）および水位の時 間変化の計算値と理論値の比較 
連続して流体粒子を発生させることができる，また，流出 境界は，流体粒子が計算領域外側に移動したとき，境界近 傍の流体粒子のみに圧力を与え，それ以外の粒子は全ての 物理量の計算を行わないようにする（越塚，2005）。

\section{（2）流入境界の精度検証}

流入境界の精度を検証するため，底面に流入領域を設 けた直方体 $\left({ }^{H} 0.3 \times{ }^{L} 0.1 \times{ }^{W} 0.1 \mathrm{~m}\right)$ の計算領域を設定する. 図-3 は，計算領域㧍よび流入速度を $0.1 \mathrm{~m} / \mathrm{s}$ としたときの水 位変化を理論值と比較した結果である.なお，水位は水 面中央付近に打ける複数の流体粒子の平均值とした。時々 刻々上昇する水面の位置は, 理論值とよく一致している ことから, 流入境界の設定に問題ないものと言える.

\section{（3）防波堤の設定および流入条件}

計算対象とする防波堤は, 青森県八戸港防波堤とし,

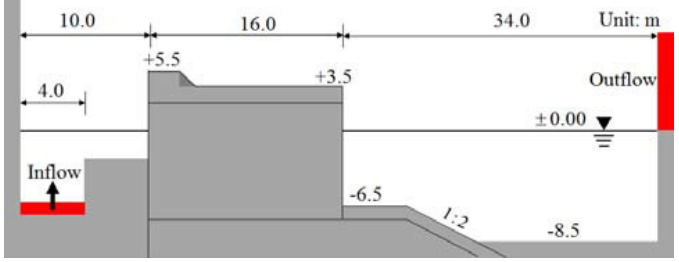

図-4計算に用いた防波堤の断面図

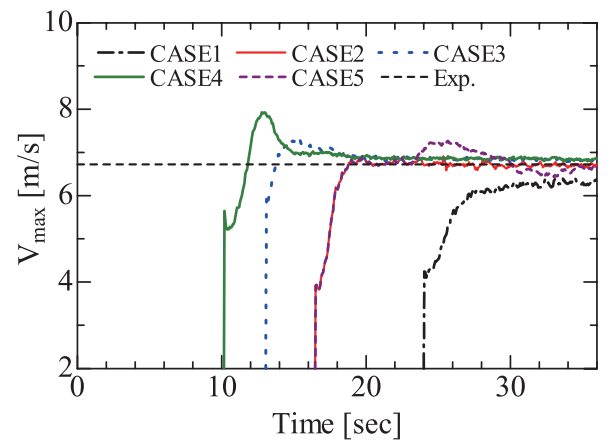

図-5 各流入条件における堤体天端上の最大流速の時間変化
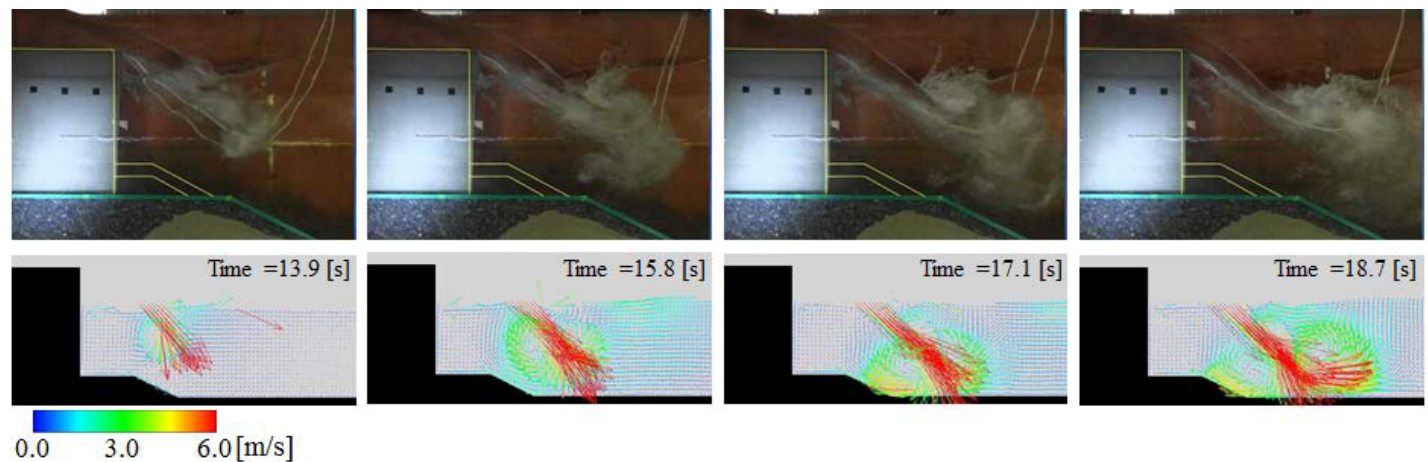

図-6 CASE4（流入速度 $3.16 \mathrm{~m} / \mathrm{s}$ ）における越流津波の堤体背後の流速ベクトル分布の時間変化（上段：半周期正弦波を用いた水理 模型実験で撮影された水塊突入過程における空間変化) 


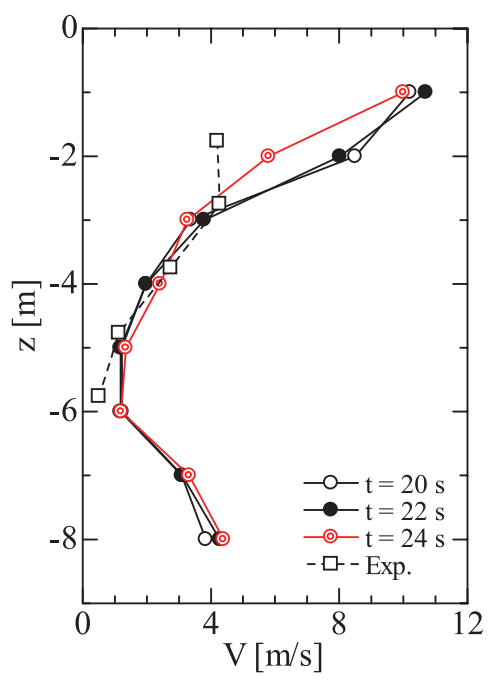

図-7＼cjkstart堤体背後のマウンド法先における流速の鉛直分布

したがって，堤体を越流する津波の流体運動を本計算 手法によって，十分に再現することが可能と言える.

図-8は，図-6に示した流速分布と同時刻における圧力 分布の時間変化を示す. 突入した水塊が底面に近づくに 連れて, マウンド法先よりも岸側の底面にかけて圧力が 大きくなり，マウンド法面から堤体背後にかけても，法 面に沿って圧力が若干大きくなることがわかる。これら の要因として，図-6に示した時刻 18.7秒の流速分布を確 認すると，底面付近では波の進行方向に非常に速い流速 が発生しており，また法面に沿って上昇するような流速 も生じていることから，この流速の作用による動圧を表 しているものと推察される。さらに，水塊突入に伴い水 面付近に時計回りの渦が発生し，時間の経過と共にマウ ンド法面上にまで到達し, 強い渦へと発達していること が図-6からわかる。この渦による巻き上げ作用および図7 に示す底面付近で見られる約 $4 \mathrm{~m} / \mathrm{s}$ の流速が持続される ことによって，マウンド被覆材の安定性を低下させ，基 礎地盤の洗掘に至ったものと推測される.

\section{5. 結論}

本研究では，海岸保全施設の粘り強さを照査するため の数值計算技術を構築することを目的としており，得ら れた主要な結論は以下の通りである.

1）ポリゴン型壁境界を適用したMPS法により，粒子型 壁境界よりも壁面近傍の流れ場および圧力場を高精度 に計算できることを示唆した。

2）防波堤を越流する津波計算では，模型実験の結果と 比較検証を行い, 堤体背後での水塊突入による渦の生 成を良好に再現することができた。

3）渦に伴う速い流れ場がマウンドの洗掘に起因する可
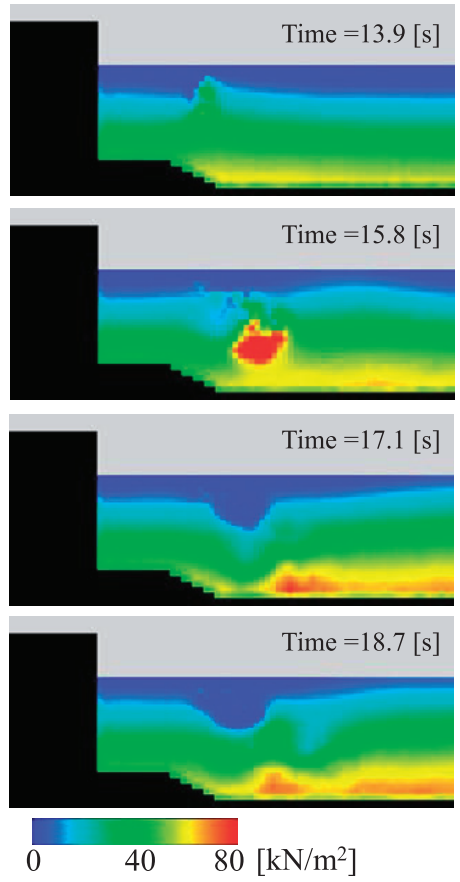

図-8 CASE4における堤体背後の圧力分布の時間変化

能性を明示し, 本計算手法が堤体背後の流体場の計算 に十分な適用性があることを実証した。

今後は, マウンドの洗掘やそれに伴う堤体の滑動・転 倒を踏まえた流体-構造-地盤の異なる三相の連成解析の 開発に取り組む予定である。

謝辞：本研究は，科学研究費助成事業（基盤（B）) 24360199 による成果であることをここに付記する。

\section{参 考 文 献}

有川太郎 - 佐藤昌治 -下迫健一郎 - 富田孝史 · 辰巳大介 - 廉 慶善・高橋研也（2012）: 釜石湾口防波堤の津波による被 災メカニズムの検討-水理特性を中心とした第一報-, 港湾 空港技術研究所資料, No.1241.

越塚誠一（2005）: 粒子法, 丸善, $34 \mathrm{p}$.

佐々木 智・小笠原敏記（2012）：MPS法におけるDelaunay 三 角形分割法によるポリゴン型壁境界モデルの開発，土木 学会論文集B2（海岸工学)，Vol. 68, No. 2, pp. I_856 I_860.

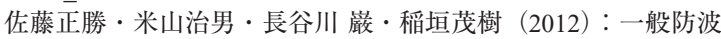
堤の津波越流による港内側マウンドの洗掘と対策，土木 学会論文集B3 (海洋開発), Vol. 68, No. 2, pp. I_252 I_257.

辻尾大樹 · 安田誠宏 · 間瀬 肇・森 信人 · 前田恭兵 · 山口 佑太（2013）：設定を超える津波に対するケーソン防波堤 の補強効果に関する実験的研究，土木学会論文集 B3（海 洋開発), Vol. 69, (印刷中).

原田隆宏・越塚誠一・島崎克教（2008）：MPS法における壁境 界計算モデルの改良, Transactions of JSCES, Paper No.20080006. 